\title{
Emission of Carbonyl Compounds from Cooking Oil Fumes in the Night Market
} Areas

\author{
Danielle E. Que ${ }^{1}$, How-Ran Chao ${ }^{2,3^{*}}$, Yi-Chyun Hsu ${ }^{4 *}$, Kangping Cui ${ }^{* *}$, Shida Chen ${ }^{*}$, \\ Lemmuel L. Tayo ${ }^{6}$, Rachelle D. Arcega ${ }^{6}$, Ying-I Tsai ${ }^{7}$, I-Cheng Lu' ${ }^{2}$, Lin-Chi Wang ${ }^{8,9,10}$, \\ Li-Hao Young ${ }^{11}$, Kwong-Leung J. Y ${ }^{12}$, Chane-Yu Lai ${ }^{13}$, Wen-Che Hou ${ }^{1}$, Sheng-Lun Lin ${ }^{8,9,10}$
}

${ }^{1}$ Department of Environmental Engineering, National Cheng Kung University, Tainan 70101, Taiwan

${ }^{2}$ Emerging Compounds Research Center, Department of Environmental Science and Engineering, College of Engineering, National Pingtung University of Science and Technology, Pingtung 91201, Taiwan

${ }^{3}$ Institute of Food Safety Management, College of Agriculture, National Pingtung University of Science and Technology, Pingtung 91201, Taiwan

${ }^{4}$ Department of Environmental Engineering, Kun Shan University, Tainan 71003, Taiwan

${ }^{5}$ School of Resources and Environmental Engineering, Hefei University of Technology, Hefei 246011, China

${ }^{6}$ School of Chemical, Biological and Materials Engineering and Sciences, Mapúa University, Intramuros, Manila 1002, Philippines

${ }^{7}$ Department of Environmental Engineering and Science, Chia Nan University of Pharmacy and Science, Tainan 71710 , Taiwan

${ }^{8}$ Department of Civil Engineering and Geomatics, Cheng Shiu University, Kaohsiung 83347, Taiwan

${ }^{9}$ Center for Environmental Toxin and Emerging-Contaminant Research, Cheng Shiu University, Kaohsiung 83347, Taiwan

${ }^{10}$ Super Micro Mass Research and Technology Center, Cheng Shiu University, Kaohsiung 83347, Taiwan

${ }^{11}$ Department of Occupational Safety and Health, College of Public Health, China Medical University, Taichung 40402, Taiwan

${ }^{12}$ Superintendent Office, Pingtung Christian Hospital, Pingtung 90059, Taiwan

${ }^{13}$ Department of Occupational Safety and Health, College of Health Care and Management, Chung Shan Medical University, Taichung 40201, Taiwan

\begin{abstract}
Cooking oil fumes (CF) coming from night market stalls exhaust contain substantial amounts of air pollutants such as carbonyl compounds that may contribute to outdoor air pollution and may have adverse health effects on the Taiwanese population. Carbonyl emission characteristics depend on several factors, which include but are not limited to, the cooking style and food material being used. The current study evaluated carbonyl compound emissions from two scenarios: a standard kitchen cooking classroom with a stack gas tunnel and night market food stalls. The different cooking styles and food types cooked using a liquefied petroleum gas (LPG) stove, such as grilled chicken with (GCS) and without sauce (GC), mixed barbecue with sauce (MBS), grilled vegetables with sauce (GVS), stir-fried oyster omelet (OM), fried Taiwanese chicken nuggets (FN) in the kitchen cooking classroom, and grilled chicken with (GCS) and without sauce (GC), stir-fried oyster omelet (OM), grilled vegetables with sauce (GVS), and fried steak (FS) in the night market were evaluated for carbonyl carbon emissions. OM from the kitchen classroom and GCS from the night market showed the highest mean total carbonyl compound concentrations $(1850 \pm 682 \mathrm{ppb}$ and $1840 \mathrm{ppb})$. Formaldehyde was found to be the most predominant carbonyl compound, with contribution percentages ranging from 70.9-99.58\% of the total carbonyl emission factors in CFs. Grilled vegetables with sauce had the highest emission factor magnitude of $274 \mu \mathrm{g} \mathrm{kg}{ }^{-1} \mathrm{wt}$. Factors such as the addition of sauce and grilling were also observed to increase carbonyl compound emissions. Corresponding health risks of carbonyl compounds in CFs for the night market vendors were also assessed. All values for
\end{abstract}

\footnotetext{
* Corresponding authors.

E-mail address: hrchao@mail.npust.edu.tw (H.R. Chao); ychsu22@yahoo.com.tw (Y.C. Hsu); cuikangping@163.com (K. Cui); 459271007@qq.com (S. Chen)
} 
cancer risk $(\mathrm{R})$ were above the standard $\mathrm{R}$ value for workplace exposure, and HQ values were all greater than 1 , suggesting a high risk for adverse health effects. Although our reported values were relatively high due to our sampling conditions, our study was first to be conducted in Taiwan and holds an important contribution to the global existing data of carbonyl compound emissions.

Keywords: Cooking oil fumes; Carbonyl compounds; Health risks; Air pollutants; Night market.

\section{INTRODUCTION}

Night markets, which are often congested with food stalls, are a cultural characteristic of Taiwan, with over 100 night markets scattered all over the country. Stir-frying and deep-frying are two common Taiwanese cooking styles, which often involve pre-heating of oil to the smoking point before putting in the ingredients, most often over natural gas or electric burners. These cooking methods produce fumes generally called cooking oil fumes or cooking fumes (CFs), which contribute to outdoor air pollution. Previous $\mathrm{CF}$ studies have found several hazardous air pollutants, including particulate matter (Gao et al., 2013), volatile organic compounds (VOCs) (Cheng et al., 2016), polycyclic aromatic hydrocarbons (PAHs) (Shen et al., 2011; Chen et al., 2019), and carbonyl compounds (Cheng et al., 2015). Among these pollutants in CFs, carbonyl compounds are one of the most severe contaminants because they pose the most damage to human health by affecting lung functions due to high emissions and carcinogenic properties.

The formation of carbonyl compounds can be attributed mainly to either direct emission sources or via atmospheric oxidation of hydrocarbons in the atmosphere (Ho et al., 2006; Murillo et al., 2012). Secondary photochemical production has also been reported to be a major carbonyl source (Sarkar et al., 2017). Some plant species are regarded as natural sources of biogenic emissions of carbonyl compounds in the environment as well (Muller et al., 2002; Wildt et al., 2003; Villanueva-Fierro et al., 2004). Additionally, incomplete combustions of carbonaceous materials contribute greatly to the major emissions of carbonyls (Ho et al., 2006). Anthropogenic sources of carbonyl compounds include cooking activities, which involve the combustion of cooking fuels such as liquefied petroleum gas, natural gas, coal, and kerosene, as well as heating of fats and oils or other biomass (Shields et al., 1995; Zhang and Smith, 1999; Lin and Liou, 2000; Schauer et al., 2001; Svendsen et al., 2002; Fullana et al., 2004a, b; Popovicheva et al., 2017). Carbonyls such as formaldehyde, acetaldehyde and propionaldehyde derived from cooking operations have been listed by Clean Air Act Amendments of 1990 as air toxics (U.S. EPA, 1991; Yao et al., 2015). Previous studies have investigated the main commercial cooking sources for carbonyl emissions. Ho et al. (2006) determined the emission levels of 13 carbonyl compounds from different restaurant exhausts based on different cooking styles and observed that formaldehyde had the most abundant distribution (12-60\%), followed by acrolein, which contributed $30 \%$, particularly in the westernstyle steak restaurant exhaust. Consequently, long-chain saturated carbonyls such as heptanal, octanal, and nonanal have been found to be at significantly high concentrations among kitchens utilizing cooking oils. Currently, localstyle fast food stops contribute the highest annual carbonyl emissions in Hong Kong. The $\mathrm{C} 1-\mathrm{C} 8$ carbonyl emissions factors (EFs) were investigated by Xiang et al. (2017) for different Chinese cooking styles. They reported that barbecue cooking had the highest carbonyl EF $\left(1.60 \mu \mathrm{g} \mathrm{kg}^{-1}\right)$, which was followed in order by frying $\left(1.53 \mu \mathrm{g} \mathrm{kg}^{-1}\right)$, teppanyaki $\left(1.23 \mu \mathrm{g} \mathrm{kg}^{-1}\right)$, and stir-frying $\left(0.699 \mu \mathrm{g} \mathrm{kg}^{-1}\right)$, while frying showed the highest health risk for carbonyl emission exposure. Meat dishes and sunflower oil were among the food materials and oil types that also carried the highest levels of carbonyl emissions. Likewise, previous studies have also reported the abundance of formaldehyde, adetaldehyde, acrolein, and nonanal in frying using various type of oils such as seed oils, canola oil, and olive oil (Schauer et al., 2002; Fullana et al., 2004a, b). In Kaohsiung, Taiwan, in both the summer and winter seasons restaurant emissions are considered to be one of the primary pollution sources, with contributions amounting to $20 \%-30 \%$ of carbonyl compounds in the atmospheric environment (Wang et al., 2010).

Carbonyl compounds are known to pose adverse health effects to the general public (Lü and Liu, 2016), and they play an important role in the existence of ground-level ozone due to their known characteristic as precursors for free radical formation (Ho et al., 2006; Alvim et al., 2018). For these reasons, the assessment of sources for carbonyl compound emissions as well as the measurement of their ambient levels have been regarded as matters of the utmost importance. Humans systemically absorb carbonyl compounds via inhalation and dermal contact due to their characteristic low boiling points as well as their high vapor pressures (Chen et al., 2012; Ramírez et al., 2012; Du et al., 2014; Villanueva et al., 2015; Sarigiannis et al., 2011). The International Agency for Research on Cancer (IARC) has classified formaldehyde, which is the most common and abundant carbonyl found in air, as a Class I human carcinogen (IARC, 2006). Acetaldehyde was also regarded as a carcinogen despite the insufficiency of investigation that documents its magnitude of carcinogenicity (Baez et al., 2003). Due to the carcinogenic properties of some carbonyls, their potential cancer/non-cancer risks to indoor populations have been assessed (Chang et al., 2019). Health risk assessments have been conducted on the adverse health effects of cooking fumes and have also reported in previous epidemiological studies. Several studies conducted in Singapore, Hong Kong, Taiwan, and Shanghai, Nanjing, and Gansu in China have reported significant correlations between cooking behavior and the risk of developing 
cancer (Ko et al., 1997; Chiu et al., 2004; Xue et al., 2016). Additionally, cooking activities, and in particular, frying, have been reported to increase the chances of lung cancer development among nonsmoking women in Hong Kong through cumulative exposure (Yu et al., 2006). Aside from cancer, a variety of respiratory ailments, such as lower airway infection in children (Smith et al., 2000), chronic obstructive pulmonary disease (Anderson, 1979), tuberculosis (Perez-Padilla et al., 2001), and asthma (Kumar et al., 2008), have been also linked to cooking fumes derived from cooking activities utilizing biofuels. Cumulative exposure to daily cooking fumes has also been associated with risks related to the development of cardiovascular disease (Dutta et al., 2012). Overall, due to the observed adverse health effects caused from cooking fume exposure, cooking, a seemingly safe daily life activity, has been placed under scrutiny (Nayek et al., 2017).

To that end, the Taiwanese government has already begun to take precautions related to carbonyl compounds emissions, particularly sources such as traditional night markets, which consist of congested rows of food stalls. Night markets are a popular cultural Taiwanese tradition. The food stalls in night markets comprise various cooking styles and food materials, which may have different carbonyl compound emissions characteristics from those of restaurants and household kitchens. Therefore, it is imperative that cooking fumes produced in these locations be investigated to develop future actions or policies that will lessen public exposure to carbonyl compounds. Currently, there is a lack of global data concerning carbonyl compound emissions from night markets, particularly in Taiwan. Also, most of the previous studies on this topic have investigated cooking fumes produced in indoor environments such as restaurants and household kitchens and other emissions sources such as industrial and vehicle exhausts (Guerra et al., 2017; Tsai et al., 2018). Our study is aimed toward developing an understanding of the carbonyl compound emission characteristics in $\mathrm{CF}$ collected from the vent hood exhausts of a standard kitchen cooking classroom based on the cooking style and food material cooked. Subsequently, the cooking fumes from Taiwanese night markets are investigated for their carbonyl compounds level and distribution. Lastly, a health risk assessment is conducted for night market vendors

\section{METHODOLOGY}

\section{Sample Collection}

This research is a part of the air pollutant in night market study (APNM) "Establishment of air pollutant emission factor in night markets of Taiwan in 2018" conducted from January to April 2018. The air pollutants in the APNM study include TPM ( $\mathrm{PM}_{2.5}$ and $\left.\mathrm{PM}_{10}\right), \mathrm{SO}_{2}, \mathrm{NO}_{\mathrm{x}}, \mathrm{CO}$, carbonyl compounds, and polycyclic aromatic hydrocarbons (PAHs). The emission factors of these air pollutants in night markets were mainly referenced from United States Environmental Protection Agency (US EPA) Test Method 5G and the final report on emissions from street vendor cooking devices (charcoal grilling) with several modifications (Lee et al., 1999a, b). According to the study design, two sampling programs were used in the present study. The first sampling program was used to determine the carbonyl compound emission factors in CF. CF samples were collected through the consistent-flow dilution tunnel after $\mathrm{CF}$ was generated in an oven. The cooking and sampling devices were established in a standard kitchen classroom. The second sampling program was used to conduct a risk assessment via direct collection of $\mathrm{CF}$ samples near a street vendor in a night market.

For the kitchen classroom sampling program, the experimental system was combined with a cooking device and a full-flow, aspirated-air stack gas tunnel equipped with an air sampling module (Fig. S1) established in the kitchen classroom of Chia Nan University of Pharmacy \& Science. The samples included CFs from grilled chicken with and without sauce (Taiwanese ji pai) (GCS and GC), mixed barbecue with sauce (MBS), grilled vegetables (green bell pepper, white onion, and green beans) with sauce (GVS), stir-fried oyster omelet (OM), and fried Taiwanese chicken nuggets (FN). Each cooking style underwent triplicate tests and sampling. Carbonyl compound sampling was carried out according to the United States Environmental Protection Agency (U.S. EPA) Method 18 (Winberry, 1990). Each CF sample was collected in a 10-L Tedlar bag (SKC-10L) placed inside a vacuum sampling box (SKC-40L). CF was sucked into the Tedlar bag through a Teflon tube, which was connected to the Tedlar bag on one end and was connected directly into the stack gas tunnel on the other end, using a sampling pump (GilAir Plus, Sensidyne, USA). Each sampling lasted 10 minutes at a fixed flow rate of $1 \mathrm{~L} \mathrm{~min}^{-1}$ (GilAir Plus, Sensidyne, USA), which was enough time to fill the 10-L Tedlar bags.

For collection of real CF samples in the night market, our researchers gathered CFs from the street vendors at Pingtung City Night Market at night (7-9 pm) from February to April 2018. CF samples from the street vendors include grilled chicken meat with and without sauce (GCS and GC), stir-fried oyster omelette (OM), grilled vegetables with sauce (GVS), and fried steak (FS). CFs from the street vendor were collected in the 10-L Tedlar bag via a Teflon tube, which was connected to the Tedlar bag on one end and was placed directly overhead the sample being cooked on the other end, using a sampling pump (Fig. S2). After sampling in the kitchen classroom and at the street vendors, all Tedlar bags were stored in a black opaque plastic bag to avoid photodegradation. The samples were transported to National Pingtung University of Science and Technology for pre-treatment and analysis.

\section{Pre-treatment}

U.S. EPA Method TO-11 and Taiwanese EPA (TEPA) Method NIEA A725.72B were used to extract and analyze the carbonyl compounds in the CFs, respectively. The CF samples, previously collected in Tedlar bags, were individually and immediately pumped through a silica cartridge coated with 2,4-dinitrophenylhydrazine (2,4-DNPH) (Dikmatech, $400 \mathrm{mg}$ ) at a flow rate of $0.150 \mathrm{~L} \mathrm{~min}^{-1}$ for 7 minutes. All carbonyl compounds were then captured 
within the cartridge and were converted to its corresponding hydrazine derivatives. The sampled cartridges were slowly eluted with $4 \mathrm{~mL}$ acetonitrile into a vial. The eluted solutions were then stored for analysis using a high performance liquid chromatograph (HPLC) with an ultraviolet (UV) $\operatorname{detector}(\lambda=360 \mathrm{~nm})$.

\section{Analysis of Carbonyl Compounds}

Twelve carbonyl compounds (acetaldehyde, butyraldehyde, crotonaldehyde, cyclohexanone, decanal, formaldehyde, heptanal, hexaldehyde, nonanal, octanal, propanaldehyde, and valeraldehyde) (external standard: M-554-DNPH-R1, AccuStandard, USA) were identified and quantified. The standard solutions were diluted to concentrations of 0.05 , $0.1,0.5,1,10$, and $20 \mathrm{ppm}$. The standard solutions and cartridge extracts were analyzed by injecting $20 \mu \mathrm{L}$ of the solution into an HPLC system (Hitachi, Japan) coupled with UV/Vis detector (Chromaster 5420, Hitachi, Japan) and a column oven (Super CO-150, Enshine, Taiwan). A separation column $(\mathrm{C} 18,4.6 \times 250 \mathrm{~mm}, 5 \mu \mathrm{m})$ was used to separate the aforementioned carbonyl compounds and was operated at room temperature. The mobile phase consisted of two solvent mixtures: solvent A, 70/30 (v/v) acetonitrile/ water and solvent $\mathrm{B}$, acetonitrile. The gradient program was operated in the following manner: First, solvent A was maintained for 20 minutes; second, solvent $\mathrm{A}$ and $\mathrm{B}$ in 15 minutes, and third, solvent $B$ was maintained for 15 minutes. The flow rate was maintained at $1.2 \mathrm{~mL} \mathrm{~min}^{-1}$.

Quality assurance and quality control (QA/QC), which included a blank test (field and cartridge blank), limits of detection (LOD), and the recovery rate of internal standards and surrogate standards, in the present study was performed according to TEPA Method NIEA A725.72B. The acceptable recovery rates of the carbonyl compounds spiked standards ranged from 80 to $120 \%$ according to the NIEA A725.72B standard. The recovery rates of the carbonyl compounds in the present study ranged from $81.6 \%$ to $119.8 \%$. The relative percent differences (RPDs) for the duplicate analyses were lower than 5\%. The LOD values of the carbonyl compounds were defined based on a 3 times signal-to-noise $(\mathrm{S} / \mathrm{N})$ ratio, which ranged between 0.023 and $0.107 \mathrm{ppb}$. The concentrations of carbonyl compounds below the LOD (limit of detection) were set at zero for further statistical analysis. All statistical analyses were performed using Statistical Product and Service Solutions version 12.0.

\section{Risk Assessment}

In the present study, non-cancer and cancer risks were assessed by considering direct inhalation exposure of the night market vendors in an outdoor environment to carbonyl compounds to night market cooking fumes, and were calculated according to (U.S. EPA, 2011; Zhang et al., 2018) guidelines as follows:

$\mathrm{HQ}=\mathrm{EC} / \mathrm{RfC}$

where HQ is the non-cancer risk (hazard quotient); EC is the inhalation exposure concentration $\left(\mathrm{mg} \mathrm{m}^{-3}\right)$, and $\mathrm{RfC}$ is the reference concentration $\left(\mathrm{mg} \mathrm{m}^{-3}\right)$. EC was calculated as follows:

$$
\mathrm{EC}=\frac{\text { carbonyl concentration } \times \mathrm{ET} \times \mathrm{EF} \times \mathrm{ED} \times 0.9}{\mathrm{AT} \times 365}
$$

where the carbonyl concentration is in $\mathrm{mg} \mathrm{m}^{-3}$; ET is the exposure time (hrs day $^{-1}$ ); EF is the exposure frequency (days year $^{-1}$ ); ED is the exposure duration (years); 0.9 is the absorption factor for both formaldehyde and acetaldehyde, and AT is the average lifetime of Taiwanese people in 2015 (years).

Formaldehyde and acetaldehyde are considered to be carcinogenic, for which the cancer risk was calculated as follows:

$\mathrm{R}=\mathrm{CDI} \times \mathrm{SF}$

where $\mathrm{R}$ is the cancer risk; $\mathrm{CDI}$ is the chronic daily intake via inhalation $\left(\mathrm{mg} \mathrm{kg}^{-1} \mathrm{day}^{-1}\right)$, and $\mathrm{SF}$ is the cancer slope factor via inhalation $\left(\left(\mathrm{mg} \mathrm{kg}^{-1} \mathrm{day}^{-1}\right)^{-1}\right)$. CDI and SF were defined as follows:

$$
\mathrm{CDI}=\frac{\text { carbonyl concentration } \times \mathrm{IR} \times \mathrm{ET} \times \mathrm{EF} \times \mathrm{ED} \times 0.9}{\mathrm{BW} \times \mathrm{AT} \times 365}
$$

$\mathrm{SF}=\frac{\mathrm{URF} \times \mathrm{BW} \times 1000}{\mathrm{IR}}$

where IR is the inhalation rate for Taiwanese adults $\left(\mathrm{m}^{-3} \mathrm{hr}\right.$ for CDI, $\mathrm{m}^{-3}$ day for SF); BW is the average body weight of Taiwanese adults in $2015(\mathrm{~kg})$; URF is the inhalation unit risk factor $\left(\mathrm{m}^{-3} \mu \mathrm{g}\right)$, and 1000 is the conversion factor to $\mathrm{mg}$.

The risk parameters used in the present study were those provided by the U.S. EPA Integrated Risk Information System (U.S. EPA-IRIS, 2017), the US Department of Health and Human Service Agency for Toxic Substances and Disease Registry (ATSDR, 2017), California Environmental Protection Agency, Air Resources Board and Office of Environmental Health Hazard Assessment (CARB/OEHHA, 2017), and from a report from the National Health Insurance Administration of the Ministry of Health and Welfare in Taiwan (MOHW, 2015). The corresponding values of the risk parameters are listed in Table S1.

\section{RESULTS AND DISCUSSION}

\section{Carbonyl Compound Concentrations in the Stack Gas from Kitchen Cooking Classroom}

The mean levels and mean total concentrations of carbonyl compounds in the exhaust coming from the stack tunnel for different cooking styles and food types in the kitchen cooking classroom were evaluated. The values are shown in Table 1 and Fig. 1. The percentage of contribution of each of the carbonyl compounds are also shown in Fig. 2(a). The oyster omelet (OM) exhaust exhibited the highest mean total carbonyl concentration, with a value of 
Table 1. Concentrations of carbonyl compounds of cooking oil fumes in the stack gas tunnel (ppb).

\begin{tabular}{|c|c|c|c|c|c|c|}
\hline \multirow{2}{*}{ Carbonyl compound } & \multicolumn{2}{|c|}{ Grilled chicken } & \multirow{2}{*}{$\begin{array}{l}\text { Grilled } \\
\text { vegetables } \\
\text { with sauce } \\
\text { (GVS) }\end{array}$} & \multirow{2}{*}{$\begin{array}{l}\text { Mixed } \\
\text { barbecue } \\
\text { with sauce } \\
(\mathrm{MBS})\end{array}$} & \multirow{2}{*}{$\begin{array}{l}\text { Oyster } \\
\text { omelet } \\
(\mathrm{OM})\end{array}$} & \multirow{2}{*}{$\begin{array}{l}\text { Fried } \\
\text { Taiwanese } \\
\text { chicken } \\
\text { nuggets (FN) }\end{array}$} \\
\hline & $\begin{array}{l}\text { with sauce } \\
\text { (GCS) }\end{array}$ & $\begin{array}{l}\text { without sauce } \\
\text { (GC) }\end{array}$ & & & & \\
\hline Formaldehyde (FA) & $1080 \pm 9.72$ & $1030 \pm 183$ & $946 \pm 119$ & $914 \pm 146$ & $1390 \pm 518$ & $942 \pm 135$ \\
\hline Acetaldehyde (AA) & $9.05 \pm 1.60$ & $12.2 \pm 0.262$ & $0.136 \pm 0.117$ & $6.55 \pm 3.58$ & $328 \pm 540$ & $47.3 \pm 30.4$ \\
\hline Propionaldehyde (PA) & $7.19 \pm 4.23$ & $9.84 \pm 1.34$ & $2.46 \pm 0.673$ & $5.93 \pm 0.369$ & $3.92 \pm 102$ & $<\mathrm{LOD}$ \\
\hline Crotonaldehyde (CA) & 5.81 & $3.68 \pm 2.50$ & $<\mathrm{LOD}$ & $<\mathrm{LOD}$ & 1.12 & $<\mathrm{LOD}$ \\
\hline Butanal (BT) & $<\mathrm{LOD}$ & $<\mathrm{LOD}$ & $<\mathrm{LOD}$ & $<\mathrm{LOD}$ & 77.9 & $<\mathrm{LOD}$ \\
\hline Mean & $1100 \pm 519$ & $1040 \pm 517$ & $969 \pm 502$ & $927 \pm 460$ & $1850 \pm 682$ & $988 \pm 497$ \\
\hline
\end{tabular}

$<$ LOD: lower than limit of detection.

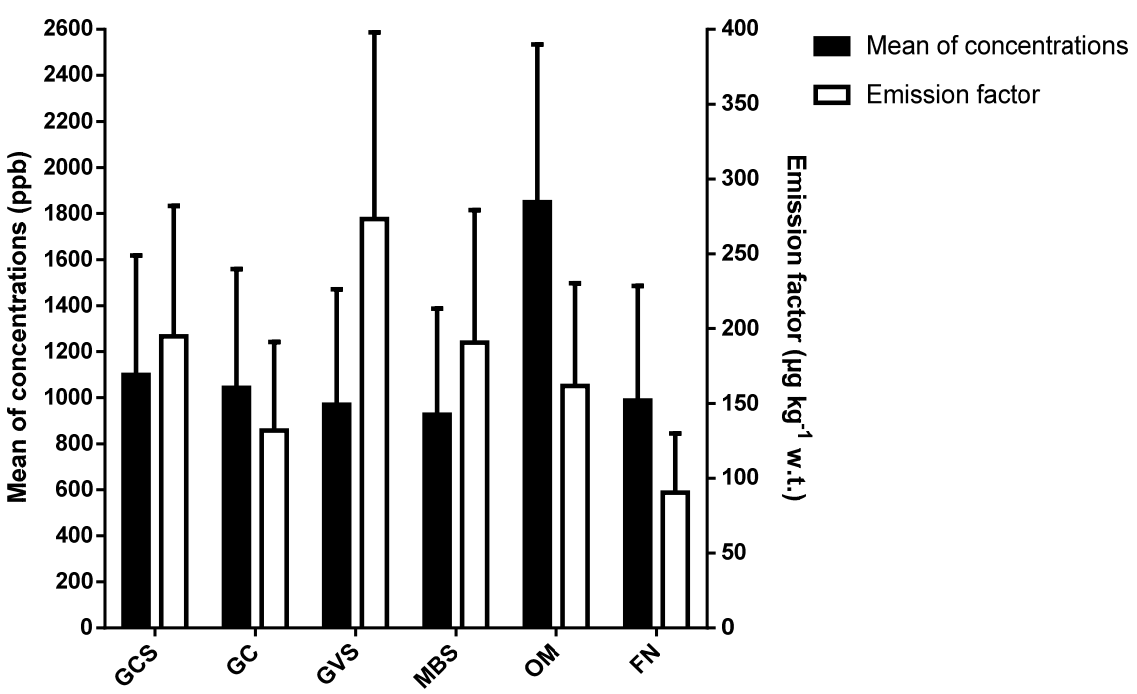

Fig. 1. Concentrations and emission factors of carbonyl compounds of cooking oil fumes from the stack gas tunnel.

$1850 \pm 682 \mathrm{ppb}$, followed by that of the grilled chicken meat with (GCS) $(1100 \pm 519 \mathrm{ppb})$ and without sauce (GC) $(1040 \pm 517 \mathrm{ppb})$, fried Taiwanese chicken nuggets $(\mathrm{CN})$ (988 $\pm 497 \mathrm{ppb})$, grilled vegetables with sauce (GVS) (969 $\pm 502 \mathrm{ppb})$, and mixed barbecue with sauce (MBS) $(927 \pm$ $460 \mathrm{ppb}$ ). Formaldehyde (FA) was the most abundant carbonyl compound among all of the cooking styles and food type emissions. OM showed the highest FA concentration of $1390 \pm 518 \mathrm{ppb}$, with a contribution accounting for $70.9 \%$ of the total OM carbonyl compound emissions. Also, high FA concentrations were observed in GCS and GC, with values of $1080 \pm 9.72 \mathrm{ppb}$ and $1030 \pm 183 \mathrm{ppb}$ while GVS, FN and MBS had concentrations of $946 \pm 119$ ppb, $942 \pm$ $135 \mathrm{ppb}$, and $914 \pm 146 \mathrm{ppb}$, respectively. Overall, the contribution percentages of FA in all food types were in the range of $70.9 \%-99.7 \%$. Acetaldehyde (AA) was the second most abundant carbonyl compound in the kitchen cooking classroom samples, with the highest concentration attributed to the OM exhaust $(328 \pm 540 \mathrm{ppb})$ and with a percentage contribution of $16.7 \%$ of the total OM carbonyl emissions. This was followed by the AA concentrations in decreasing order: $\mathrm{CN}$ (47.3 $\pm 30.4 \mathrm{ppb}), \mathrm{GC}(12.2 \pm$ $0.262 \mathrm{ppb}), \mathrm{GCS}(9.05 \pm 1.60 \mathrm{ppb}), \mathrm{MBS}(6.55 \pm 3.58 \mathrm{ppb})$, and GVS $(0.136 \pm 0.117 \mathrm{ppb})$. Propionaldehyde (PA) levels were the most abundant in the GC exhaust at $9.84 \pm$
$1.34 \mathrm{ppb}$ followed by that of the GCS $(7.19 \pm 4.23 \mathrm{ppb})$, $\operatorname{MBS}(5.93 \pm 0.369 \mathrm{ppb}), \mathrm{OM}(3.92 \pm 102 \mathrm{ppb})$, and GVS $(2.46 \pm 0.673 \mathrm{ppb})$, respectively. No PA levels were found in the FN exhaust. Although the PA level of OM was considerably lower than the other kitchen cooking classroom food types, it contributed $8.1 \%$ of the total carbonyl compounds detected in the exhaust. Crotonaldehyde (CA) levels were only detected in GCS (5.81 ppb), GC (3.68 \pm $2.50 \mathrm{ppb})$, and OM (1.12 ppb), and Butanal (BT) levels were only detected in OM at $77.9 \mathrm{ppb}$.

\section{Carbonyl Compound Concentrations in the Night Market}

In this study, the carbonyl compounds concentrations coming from the Taiwanese night market cooking fumes (Table 2) were also quantified, and their profile distribution is shown in Fig. 2(b). In this location, the cooking styles and food types considered were grilled chicken meat with sauce (GCS) and without sauce (GC), oyster omelet (OM), grilled vegetables with sauce (GVS), and fried steak (FS). GCS showed the highest total carbonyl compound mean concentrations of $1840 \mathrm{ppb}$, followed by FS (1300 ppb), OM (959 ppb), GC (840 ppb), and GVS (784 ppb), in that order. FA levels detected in the night market cooking oil fumes were the highest among all the carbonyl compounds, with concentrations observed in decreasing order as GCS 


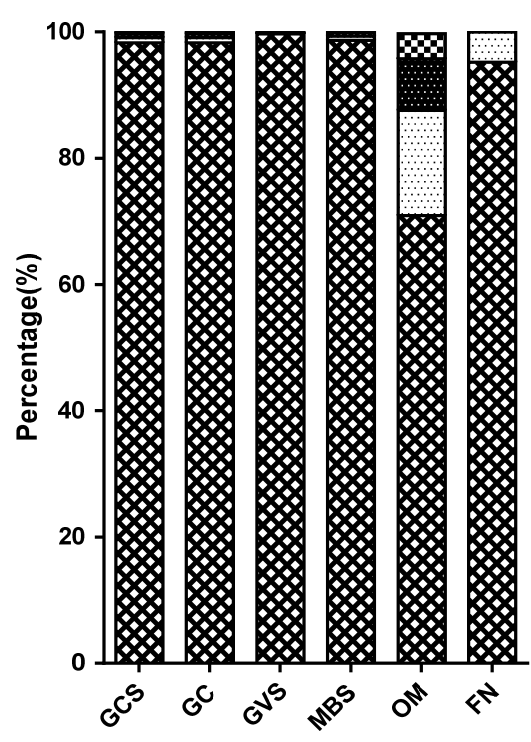

(a)
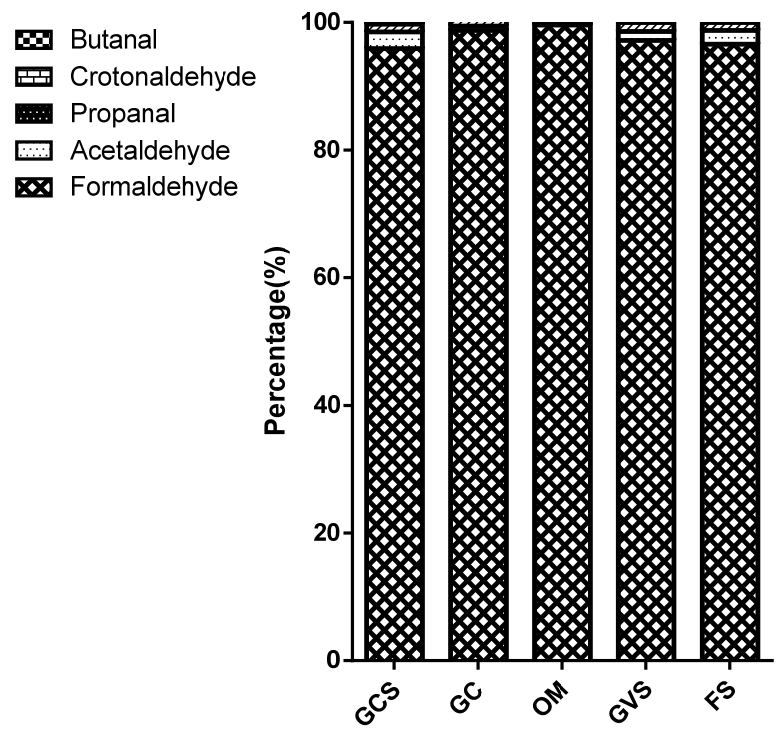

(b)

Fig. 2. Composition percentage of carbonyl compounds in the night market cooking fumes (A) collection samples in stack gas tunnel from the standard kitchen classroom (B) collection samples from the outdoor food vendors in the night market.

Table 2. Mean concentrations of carbonyl compounds in night market cooking oil fumes (ppb) (pooled samples).

\begin{tabular}{llllll}
\hline \multirow{2}{*}{$\begin{array}{l}\text { Carbonyl } \\
\text { compound }\end{array}$} & \multicolumn{2}{c}{ Grilled chicken } & $\begin{array}{l}\text { Oyster omelet } \\
(\text { OM) }\end{array}$ & $\begin{array}{l}\text { Grilled vegetables } \\
\text { with sauce (GVS) }\end{array}$ & $\begin{array}{l}\text { Fried steak } \\
(\mathrm{FS})\end{array}$ \\
\cline { 2 - 5 } Formaldehyde (FA) & with sauce (GCS) & without sauce (GC) & 955 & 762 & 1240 \\
Acetaldehyde (AA) & 4770 & 830 & 0.070 & 10.8 & 27.5 \\
Propionaldehyde (PA) & 22.3 & 5.87 & 3.92 & 10.9 & 16.3 \\
Crotonaldehyde (CA) & 4.99 & 4.63 & $<$ LOD & $<$ LOD & 7.62 \\
Total & 1840 & $<$ LOD & 959 & 784 & 1300 \\
\hline
\end{tabular}

< LOD: lower than limit of detection.

$(1770 \mathrm{ppb})>\mathrm{FS}(1240 \mathrm{ppb})>\mathrm{OM}(955 \mathrm{ppb})>\mathrm{GC}(830 \mathrm{ppb})$ $>$ GVS (762 ppb). The FA distribution percentages in all of the night market samples were observed to be in the range of $95.5 \%-99.58 \%$. AA was also detected among the night market cooking oil fumes, with the highest concentration coming from GCS at $48.1 \mathrm{ppb}$, with a percentage contribution of $2.61 \%$. Other night market samples showed AA concentrations of $27.5 \mathrm{ppb}$ (FS), $10.8 \mathrm{ppb}$ (GVS), $5.87 \mathrm{ppb}$ (GC), and $0.070 \mathrm{ppb}(\mathrm{OM})$, with contribution percentages within the range of $0.007 \%-2.61 \%$. In addition, PA concentrations were also detected in decreasing order as $\operatorname{GCS}(22.3 \mathrm{ppb})>\mathrm{FS}(16.3 \mathrm{ppb})>\operatorname{GVS}(10.9 \mathrm{ppb})>$ $\mathrm{GC}(4.63 \mathrm{ppb})>\mathrm{OM}(3.92 \mathrm{ppb})$. CA was only detected in GCS (4.99 ppb) and FS (7.62 ppb).

In a study conducted by Ho et al. (2006) evaluating carbonyl emissions from commercial cooking sources in Hong Kong, the total aldehyde emission was observed to be in the range of 81.8-831 ppb, while Huang et al. (2011) reported that the total carbonyl levels from Hong Kong residential cooking activities were in the range of 185$241 \mu \mathrm{g} \mathrm{m}^{-3}$. Cheng et al. (2015) determined the Beijing restaurants exhaust total carbonyl levels to be 115$1040 \mu \mathrm{g} \mathrm{m}^{-3}$, which was relatively higher compared to another Chinese study, which reported the exhaust of commercial restaurants to have a total carbonyl compound emission level range of 68-314 $\mu \mathrm{g} \mathrm{m}^{-3}$ (Dai et al., 2018). Taiwanese studies have reported total carbonyl emission levels from restaurant kitchen areas (8.59-45.5 ppb), dining areas (3.08-45.1 ppb), and restaurant exhausts (58$132 \mathrm{ppb})$ with different cooking styles.

\section{Emission Factors of Carbonyl Compounds in the Stack Gas from Kitchen Cooking Classroom}

The emission factors related to the different cooking styles and food types in the kitchen classroom are listed in Table 3 and Fig. 1. The highest total carbonyl compound emission factor was determined to be associated with GVS, with a value of $273 \pm 45.0 \mu \mathrm{g} \mathrm{kg}^{-1}$ wt. GCS, and MBS showed similar total carbonyl compound emission factors with values of $194 \pm 87.3 \mu \mathrm{g} \mathrm{kg}^{-1}$ wt. and $191 \pm$ $88.6 \mu \mathrm{g} \mathrm{kg}^{-1}$ wt., respectively. These emission factor values were followed by those of OM $\left(162 \pm 68.7 \mu \mathrm{g} \mathrm{kg}^{-1} \mathrm{wt}\right.$.), GC (132 $\pm 59.3 \mu \mathrm{g} \mathrm{kg}^{-1} \mathrm{wt}$.), and FN $\left(90.4 \pm 39.6 \mu \mathrm{g} \mathrm{kg}^{-1}\right.$ wt. $)$. Among all of the carbonyl compounds, the emission factors for FA were determined to be the highest, with varying values in the range of $86.3-273 \mu \mathrm{g} \mathrm{kg}^{-1}$ wt. In relation to the kitchen cooking classroom samples, the FA emission factors were, in decreasing order, GVS (273 \pm $44.9 \mu \mathrm{g} \mathrm{kg}^{-1}$ wt. $)>\operatorname{GCS}\left(192 \pm 30.7 \mu \mathrm{g} \mathrm{kg}^{-1}\right.$ wt. $)>$ MBS $\left(188 \pm 60.8 \mu \mathrm{g} \mathrm{kg}^{-1}\right.$ wt. $)>\mathrm{OM}\left(138 \pm 77.3 \mu \mathrm{g} \mathrm{kg}^{-1}\right.$ wt. $)>$ 
Table 3. Carbonyl emission factors ( $\mu \mathrm{g} \mathrm{kg}^{-1} \mathrm{wt}$.) of cooking oil fumes in the stack gas tunnel.

\begin{tabular}{|c|c|c|c|c|c|c|}
\hline \multirow{3}{*}{ Carbonyl compound } & \multicolumn{6}{|c|}{ Emission factor $\left(\mu \mathrm{g} \mathrm{kg}^{-1} \mathrm{wt}.\right)$} \\
\hline & \multicolumn{2}{|c|}{ Grilled chicken } & \multirow{2}{*}{$\begin{array}{l}\text { Grilled } \\
\text { vegetables } \\
\text { with sauce } \\
\text { (GVS) }\end{array}$} & \multirow{2}{*}{$\begin{array}{l}\text { Mixed } \\
\text { barbecue } \\
\text { with sauce } \\
\text { (MBS) }\end{array}$} & \multirow{2}{*}{$\begin{array}{l}\text { Oyster } \\
\text { omelet } \\
(\mathrm{OM})\end{array}$} & \multirow{2}{*}{$\begin{array}{l}\text { Fried } \\
\text { Taiwanese } \\
\text { chicken } \\
\text { nuggets (FN) }\end{array}$} \\
\hline & $\begin{array}{l}\text { with sauce } \\
\text { (GCS) }\end{array}$ & $\begin{array}{l}\text { without sauce } \\
\text { (GC) }\end{array}$ & & & & \\
\hline Formaldehyde (FA) & $192 \pm 30.7$ & $129 \pm 28.6$ & $273 \pm 44.9$ & $188 \pm 60.8$ & $138 \pm 77.3$ & $86.3 \pm 21.9$ \\
\hline Acetaldehyde (AA) & $1.57 \pm 0.080$ & $1.28 \pm 1.13$ & $0.030 \pm 0.030$ & $1.23 \pm 0.420$ & $13.0 \pm 18.3$ & $4.04 \pm 1.93$ \\
\hline Propionaldehyde (PA) & $1.20 \pm 0.480$ & $1.05 \pm 0.950$ & $0.710 \pm 0.220$ & $1.20 \pm 0.230$ & $10.4 \pm 18.0$ & $<\mathrm{LOD}$ \\
\hline Crotonaldehyde (CA) & $0.280 \pm 0.480$ & $0.410 \pm 0.480$ & $<\mathrm{LOD}$ & $<\mathrm{LOD}$ & $<\mathrm{LOD}$ & $<$ LOD \\
\hline Mean & $194 \pm 87.3$ & $132 \pm 59.3$ & $274 \pm 45.0$ & $191 \pm 88.6$ & $162 \pm 68.7$ & $90.4 \pm 39.6$ \\
\hline
\end{tabular}

$<$ LOD: lower than limit of detection.

$\mathrm{GC}\left(129 \pm 28.6 \mu \mathrm{g} \mathrm{kg}^{-1}\right.$ wt. $)>\mathrm{FN}\left(86.3 \pm 21.9 \mu \mathrm{g} \mathrm{kg}^{-1}\right.$ wt. $)$. AA emission factors were also determined, and their values were in decreasing order in relation to the kitchen cooking classroom samples: OM $\left(13 \pm 18.3 \mu \mathrm{g} \mathrm{kg}^{-1} \mathrm{wt}\right.$. $)>\mathrm{FN}(4.04$ $\pm 1.93 \mu \mathrm{g} \mathrm{kg}^{-1}$ wt. $)>\operatorname{GCS}\left(1.57 \pm 0.0800 \mu \mathrm{g} \mathrm{kg}^{-1}\right.$ wt. $)>\mathrm{GC}$ $\left(1.28 \pm 1.13 \mu \mathrm{g} \mathrm{kg}^{-1}\right.$ wt. $)>\operatorname{MBS}\left(1.23 \pm 0.420 \mu \mathrm{g} \mathrm{kg}^{-1}\right.$ wt. $)$ $>\operatorname{GVS}\left(0.030 \pm 0.030 \mu \mathrm{g} \mathrm{kg}^{-1}\right.$ wt. $)$. The highest PA emission factor was associated with OM (10.41 \pm 18.04 $\mu \mathrm{g} \mathrm{kg}^{-1}$ wt.). Similar PA emission factors were observed in both GCS $\left(1.20 \pm 0.480 \mu \mathrm{g} \mathrm{kg}^{-1}\right.$ wt.) and MBS (1.20 \pm $0.230 \mu \mathrm{g} \mathrm{kg}^{-1}$ wt.), while PA emission factors in GC and GVS were measured to be $1.05 \pm 0.950 \mu \mathrm{g} \mathrm{kg}^{-1}$ wt. and $0.710 \pm 0.220 \mu \mathrm{g} \mathrm{kg}^{-1} \mathrm{wt}$., respectively. CA was observed to have the lowest emission factors in relation to the kitchen cooking classroom cooking styles and food types, GC $(0.410$ $\pm 0.480 \mu \mathrm{g} \mathrm{kg}^{-1}$ wt.) and GCS $\left(0.280 \pm 0.480 \mu \mathrm{g} \mathrm{kg}^{-1}\right.$ wt. $)$, respectively. Our study was limited to only simulation of the carbonyl compound emission factors in $\mathrm{CF}$ from the stack gas tunnel in the kitchen cooking classroom because this study was lacking some information or parameters (i.e., dilution time, fuel, cooking habits) from the night market cooking oil fume sample that are important in the calculation of the emission factors, such as the air dilution levels. In addition, night market stall cooks perform multiple tasks at the same time, thereby making the determination of the emission factors illogical.

In this study, food cooked by grilling such as GVS, GCS, and MBS showed higher carbonyl emission factors. According to previous studies, emission factors of carbonyl compounds can be influenced largely by the cooking and exhaust temperatures. High cooking temperature has been reported to accelerate fatty acid breakdown (as based on the cooking oil and food type) that may lead to higher emission of aldehydes, while high exhaust temperatures have been attributed to a favored formation of low molecular weight (LMW) carbonyl species such as formaldehyde due to the accelerated degradation process of high molecular weight (HMW) carbonyl species (Liu et al., 2009; Klein et $a l ., 2018)$. However, increasing the temperature can also eliminate LMW carbonyls such as formaldehyde (Xiang et al., 2017). Grilling exhaust has been reported to reach temperatures of $34.4^{\circ} \mathrm{C}$ as compared to that of stir-frying $\left(31.2-33.8^{\circ} \mathrm{C}\right)$ and deep-frying $\left(24.0^{\circ} \mathrm{C}\right)$ (Ho et al., 2006). Gao et al. (2013) also reported that particle emissions from cooking fumes are more likely to be dependent on the heating temperature rather than the cooking oil type. Aside from the temperature, Klein et al. (2018) reported that the use of oils as well as the cooking oil surface are important considerations that can influence the emission factors related to carbonyl compounds. Peng et al. (2017) indicated that utilizing a more gentle cooking style such as stir-frying, as well as using cooking oils with low unsaturated fatty acid content, can help reduce acetaldehyde emissions. As for the smaller aldehydes, they mostly come from cooking meat and not from the cooking oil itself (Klein et al., 2018).

Although GC is classified as a grilled food, its emission factor is lower than that of the OM, which can be attributed to the fact that there was no sauce added to GC. As shown in Fig. 3, the grilled chicken meat carbonyl emission factor varied based on the addition/no addition of sauce. Therefore, the sauce is an important factor in the determination of the carbonyl emission factor. Overall, higher emission factors were observed in foods cooked with sauce. Our study results provided an indication of the influence of additional ingredients such as sauce and condiments on increasing

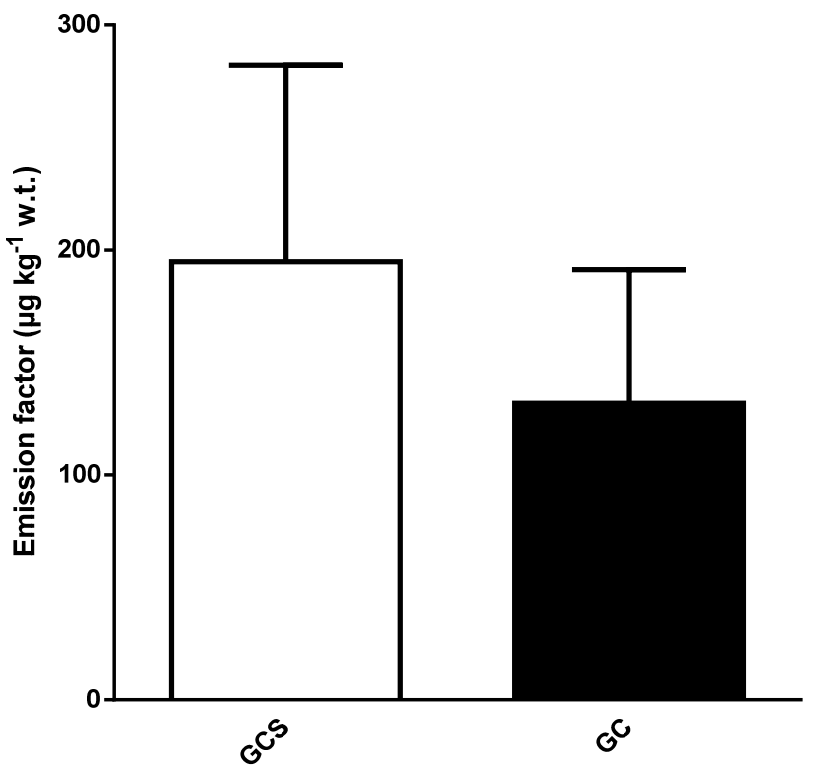

Fig. 3. Emission factors of carbonyl compounds in cooking oil fumes with different type of grilled chicken meat. 
emission factor of carbonyl compounds. For example, a commonly used sauce in cooking, soy sauce, was determined to have high levels of acetaldehyde, and fermented soy sauce was reported to contain 20 carbonyl compounds (Yanfang and Wenyi, 2009; Sun et al., 2010). Non-grilled food such as OM and FN were observed to have high total carbonyl compound mean concentrations. However, the emission factors were relatively lower as compared to their respective concentrations, which may be attributed to the frying duration (Fullana et al., 2004b). OM showed the highest emission factor among non-grilled food, which may be due to it being composed of more ingredients and additives such as sauce as compared to FN.

In a study conducted by Xiang et al. (2017) investigating the impact of carbonyl compound emission factors from different Chinese cooking methods, barbeque was observed to have the highest carbonyl compound emission factor (1.60 $\mathrm{g} \mathrm{kg}^{-1} \mathrm{wt}$.) as compared to frying (1.53 $\mu \mathrm{g} \mathrm{kg}^{-1}$ wt.), teppanyaki (1.23 $\mu \mathrm{g} \mathrm{kg}^{-1} \mathrm{wt}$.), and stirfrying (0.699 $\mathrm{gg} \mathrm{kg}^{-1}$ wt.) due to higher fat content especially in the case of pork that triggers the peroxyl radical reaction. Grilling vegetables has been observed to have lower emission factors as compared to grilling meat (Schauer et al., 2002). However, GVS was observed to have a higher emission factor as compared to the other grilled foods containing meat such as GCS and MBS. This may be attributed to the fact that GVS had a slightly longer cooking duration as compared to GCS and that chicken does not have a high fat content as compared to its other meat counterparts such as pork and beef. Fullana et al. (2004b) indicated the importance of the cooking duration in the evaluation of carbonyl emission sources. Although GVS and MBS were cooked for the same period of time, MBS components did not entirely consist of meat, and the meat component also contained low levels of fatty acids. Another important consideration would be the amount of sauce that was added to each of the grilled foods. GVS may have had more sauce as compared to the others.

Lastly, as Zhang and Smith (1999) indicated, one may also consider the type of cooking stove and fuel since these can also affect the carbonyl emission characteristics of a source. In this study, all stoves generated carbonyl compounds while the use of kerosene and LPG as fuel generated the most carbonyl compound emissions. Although the emission factors for the night market cooking oil fume carbonyl compounds were not determined in this study, the emission factor from the kitchen cooking classroom may provide a glimpse of its emission factor values. However, the sampling conditions are relatively different. Thus, we still need to consider other factors such as air dilution, other sources of carbonyl emissions (e.g., vehicles), etc. that may influence the observed carbonyl compound emissions in the night market.

\section{Risk Assessment of the Exposure to Night Market Cooking Oil Fumes}

The lifetime cancer risk (R) and the hazard quotient (HQ) were determined to assess the risk of the exposure of night market vendors to formaldehyde and acetaldehyde in the cooking oil fumes during operating hours (Table 4). The FA cancer risk values for GCS, GC, OM, GVS, and FS were found to be $9.65 \times 10^{-3}, 4.54 \times 10^{-3}, 5.22 \times 10^{-3}$, $4.17 \times 10^{-3}$, and $6.80 \times 10^{-3} \mathrm{mg} \mathrm{kg}^{-1} \mathrm{day}^{-1}$, while the AA cancer risk values observed were $1.83 \times 10^{-4}, 2.24 \times 10^{-5}$, $2.60 \times 10^{-7}, 4.09 \times 10^{-5}$, and $1.05 \times 10^{-4} \mathrm{mg} \mathrm{kg}^{-1} \mathrm{day}^{-1}$. The night market cooking fume cancer risk values in this study were above the acceptable lifetime cancer risk standard value of $10^{-6}$, which suggests the importance of promulgating emission regulations especially for people who regularly work and are exposed to these conditions. All of the night market sample HQ values were greater than 1 except that of the OM acetaldehyde HQ value. HQ values $>1$ are an indication of higher risk to adverse health effects with long-term exposure to these harmful compounds. The estimated toxicity and exposure for FA and AA are shown in Figs. 4(a) and 4(b). Overall, GCS showed the highest toxicity and exposure as compared to the other night market food types for FA and AA emissions. The lowest FA and AA toxicity and exposure were observed for GVS and OM. Our results indicate an association of the type of food and cooking style with the extent of toxicity and exposure to emitted carbonyl compounds, which are important factors when evaluating emission sources and occupational risk.

As compared to the FA cancer risk values of the grilled Taiwanese night market food in this study, the $\mathrm{R}$ values for the Chinese and Korean barbeque FA emissions in commercial restaurants in China were found to be lower, with values of $1.46 \times 10^{-4}$ and $0.75 \times 10^{-4}$ (Dai et al., 2018). While the AA cancer risk values in our study for grilled food in the night market were higher for GC and lower for GVS when compared to the Chinese and Korean barbeque $\mathrm{R}$ values for $\mathrm{AA}$ at $0.18 \times 10^{-4}$ and $0.13 \times 10^{-4}$ in a

Table 4. Cancer risk (R) assessments of exposure to formaldehyde and acetaldehyde for the night market vendors during operating hours.

\begin{tabular}{|c|c|c|c|c|c|}
\hline \multirow[t]{3}{*}{ Carbonyl compound } & \multicolumn{5}{|c|}{ Cancer risk } \\
\hline & \multicolumn{2}{|c|}{ Grilled chicken } & \multirow{2}{*}{$\begin{array}{l}\text { Oyster omelet } \\
(\mathrm{OM})\end{array}$} & \multirow{2}{*}{$\begin{array}{l}\text { Grilled vegetables } \\
\text { with sauce (GVS) }\end{array}$} & \multirow{2}{*}{$\begin{array}{l}\text { Fried steak } \\
\text { (FS) }\end{array}$} \\
\hline & with sauce (GCS) & without sauce (GC) & & & \\
\hline Formaldehyde (FA) & $9.65 \times 10^{-3}$ & $4.54 \times 10^{-3}$ & $5.22 \times 10^{-3}$ & $4.17 \times 10^{-3}$ & $6.80 \times 10^{-3}$ \\
\hline \multirow[t]{2}{*}{ Acetaldehyde (AA) } & $1.83 \times 10^{-4}$ & $2.24 \times 10^{-5}$ & $2.60 \times 10^{-7}$ & $4.09 \times 10^{-5}$ & $1.05 \times 10^{-4}$ \\
\hline & \multicolumn{5}{|c|}{ Hazard quotient non-cancer risk } \\
\hline Formaldehyde (FA) & 4.02 & 1.89 & 2.17 & 1.74 & 2.83 \\
\hline Acetaldehyde (AA) & 12.3 & 1.51 & 0.0175 & 2.76 & 7.04 \\
\hline Total & 16.3 & 3.40 & 2.19 & 4.49 & 9.87 \\
\hline
\end{tabular}


(a)

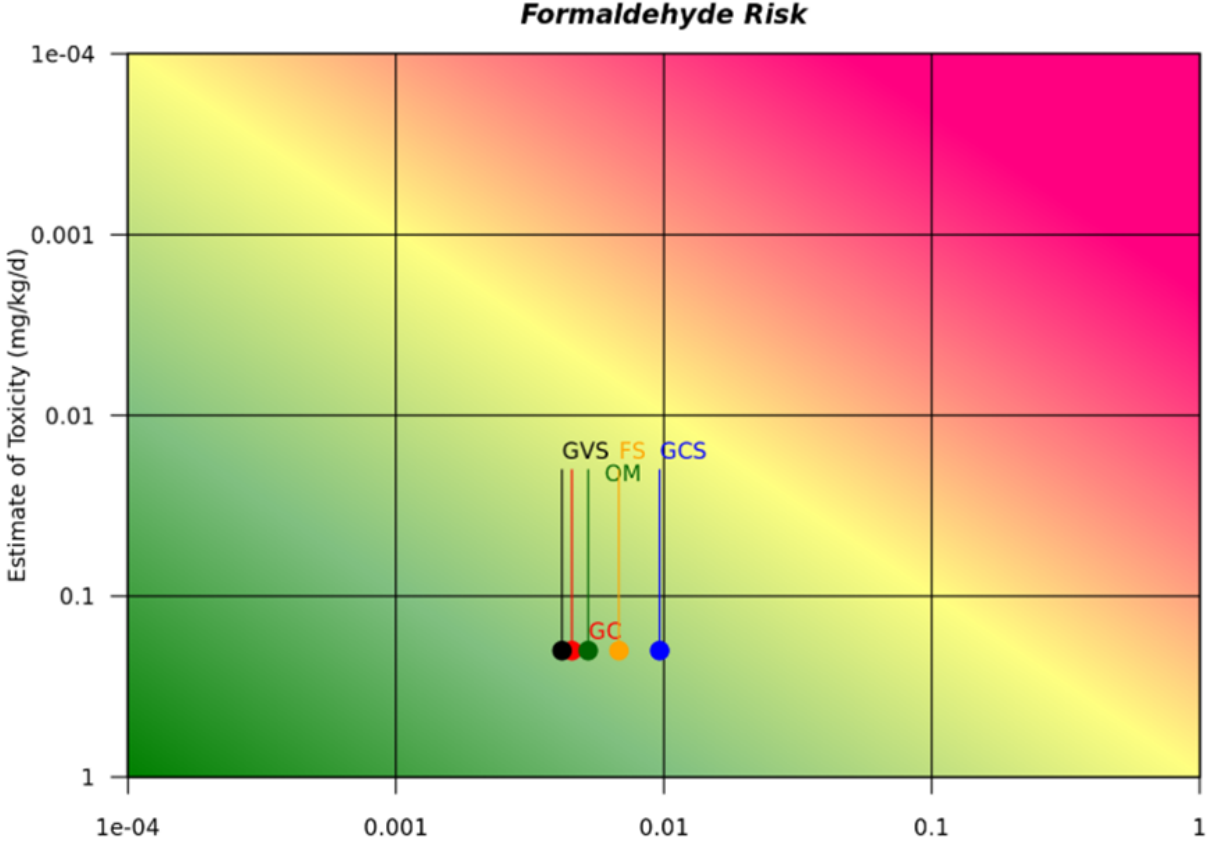

Estimate of Exposure $(\mathrm{mg} / \mathrm{kg} / \mathrm{d})$

(b)

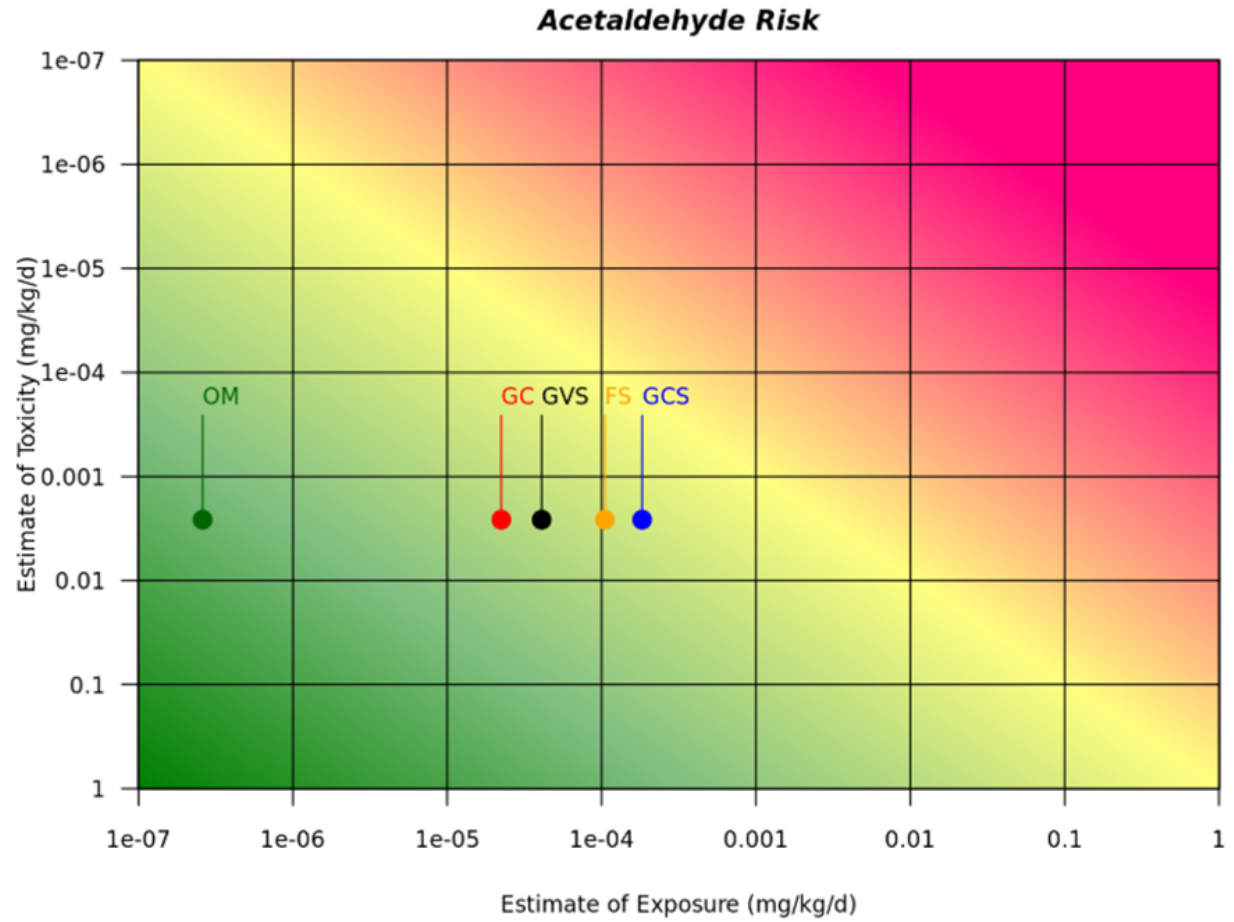

Fig. 4. Noncancer risks of (a) formaldehyde and (b) acetaldehyde from cooking oil fumes in a real night market scenario based on occupational exposure.

study conducted by Dai et al. (2018). Aside from barbeque, Dai et al. (2018) also reported the FA and AA cancer risk values of food types such as Szechwan hotpot $\left(0.27 \times 10^{-4}\right.$ and $\left.0.29 \times 10^{-4}\right)$, Hunan cuisine $\left(0.50 \times 10^{-4}\right.$ and $\left.0.13 \times 10^{-4}\right)$, Shaanxi noodle $\left(0.35 \times 10^{-4}\right.$ and $\left.0.10 \times 10^{-4}\right)$, Chinese vegetarian food $\left(0.44 \times 10^{-4}\right.$ and $\left.0.11 \times 10^{-4}\right)$, Italian food $\left(0.26 \times 10^{-4}\right.$ and $\left.0.06 \times 10^{-4}\right)$, and Indian food $\left(0.66 \times 10^{-4}\right.$ and $\left.0.19 \times 10^{-4}\right)$, respectively. Overall, the FA cancer risk values in our study were higher, while the R values of AA were relatively comparable. In addition, Taiwanese night market food cancer $\mathrm{R}$ values were also higher as compared to those of the home kitchens in a Hong Kong study conducted by Huang et al. (2011), with FA and A cancer risk values of $1.05 \times 10^{-5}$ and $3.05 \times 10^{-6}$ (Dwelling A), and $1.57 \times 10^{-5}$ (Dwelling $\mathrm{B}$ ). The $\mathrm{R}$ values of both FA and AA for the Taiwanese night market food were also 
relatively higher as compared to that of other food types for total $\mathrm{R}$ values coming from the different cooking styles in restaurant dining areas in Taiwan such as Chinese buffet $\left(1.96 \times 10^{-8}\right)$ and hotpot $\left(1.31 \times 10^{-6}\right)$, Japanese barbeque $\left(1.15 \times 10^{-6}\right)$, Western fast food $\left(3.88 \times 10^{-8}\right)$, Chinesewestern mixed style $\left(5.10 \times 10^{-8}\right)$, and Chinese stir-frying $\left(5.67 \times 10^{-8}\right)($ Cheng et al., 2016). Similarly, our FA and AA values were also higher as compared to those of the total $\mathrm{R}$ values of cooking styles simulated in a Chinese lab, including barbeque $\left(2.35 \times 10^{-7}\right)$, teppanyaki $\left(2.08 \times 10^{-7}\right)$, frying $\left(2.66 \times 10^{-7}\right)$, and stir-frying $\left(1.51 \times 10^{-7}\right)$ (Xiang et al., 2017). Our reported total HQ values were also higher as compared to the reported values from a study conducted by Cheng et al. (2016) except for the Japanese barbeque, which had a higher value of 18.81. One possible reason for the high values determined in this study is the fact that the sampling of the carbonyl compounds in the night market cooking fumes did not allow for any air dilution therefore resulting in more concentrated levels of the carbonyl compounds detected in the cooking fume samples from the different Taiwanese night market cooking styles, thereby increasing the cancer risk value. However, our reported values may have significant contributions to the global data on carbonyl compounds and for the implementation of regulations regarding the cooking fume carbonyl emission standards in Taiwanese night markets. In addition, people exposed to this kind of working conditions are advised to take precautions when being exposed to the cooking fumes coming from their respective food stall exhausts.

In conclusion, we cannot directly compare our values to previous studies due to our study having a different sampling condition and several limitations. Firstly, we directly sampled the CF exhausts, which only allowed aspirated-air dilutions in the present study, thereby resulting in detection of higher levels and emissions factors, leading to calculations indicating higher health risk values, and the carbonyl compounds in the night market were collected during the actual night market operating hours. The difference in our sampling conditions from those of previous studies make our study difficult to compare with the existing global data. Secondly, the limitations include the complexity of the night market sampling itself, which is attributed to the food vendors using different types of sauce and utilizing the same cooking styles but different food materials. Also, the cooking stoves, ovens, and the fuel types used were different and were not considered in this study. Lastly, our study also did not consider the cooking habits of the night market food vendors, which may have some effect on the carbonyl compound emissions. Although our study poses these limitations, our study was the first in which an evaluation of carbonyl compound emissions in a night market was conducted, which may have an important role in the regulation of carbonyl emissions coming from CFs and in the evaluation of its impact on human health especially because night markets are important culturally in Taiwan. Our reported values may provide significant contributions to the global data on indoor and outdoor carbonyl compounds as well.

\section{CONCLUSIONS}

Carbonyl compound emissions in cooking fumes and corresponding cancer/non-cancer risks resulting from different cooking styles in both a kitchen cooking classroom setting and in Taiwanese night market food stalls were evaluated in this study. Overall, formaldehyde was the most dominant carbonyl in all of the cooking fume samples. In terms of cooking style, grilled food had higher carbonyl compound emissions as compared to the other cooking styles. Important factors such as cooking and exhaust temperatures, cooking duration, the type of food material, and cooking oil were shown to have contributions to the variations in carbonyl compound emissions. The addition of sauce is also an important factor in the increase of carbonyl compound levels due to the fact that sauce contains additional components that may contribute to more carbonyl compound emissions as compared to food without additional sauce. The highest emission factor was observed for the kitchen cooking classroom grilled vegetables with sauce as compared to the other food types possibly due to its longer cooking period and sauce components. For the risk assessment of night market vendors, our values exceeded the standard cancer risk value, and the HQ values were all $>1$, suggesting that there is a higher risk of adverse health effects for occupational workers. Although our reported values were relatively high due to the absence of air dilution, and several other factors that may have had an effect on the evaluation of carbonyl compounds in the night market were not taken into consideration, our study is considered to be the first in Taiwan on this topic, and it provides an important contribution to the existing global data on carbonyl compound emissions.

\section{ACKNOWLEDGMENTS}

This study was supported by a grant from the Ministry of Science and Technology (MOST 106-EPA-F-019-001). We acknowledge Dr. Yan-You Gou and Mr. To-Yao Chang from National Pingtung University of Science and Technology for assisting us in the collection of samples and analysis of the carbonyl compounds. We also want to thank the team members of Chia Nan University of Pharmacy \& Science and China Medical University.

\section{DISCLAIMER}

The authors declare no conflicts of interest.

\section{SUPPLEMENTARY MATERIAL}

Supplementary data associated with this article can be found in the online version at http://www.aaqr.org.

\section{REFERENCES}

Alvim, D.S., Gatti, L.V., Corrêa, S.M., Chiquetto, J.B., Santos, G.M., de Souza Rossatti, C., Pretto, A., Rozante, J.R., Figueroa, S.N., Pendharkar, J. and Nobre, P. (2018). 
Determining VOCs reactivity for ozone forming potential in the megacity of Sau Paulo. Aerosol Air Qual. Res. 18: 2460-2474.

Anderson, H.R. (1979). Chronic lung disease in the Papua New Guinea highlands. Thorax 34: 647-653.

ATSDR (2017). Agency for toxic substances and disease registry (ATSDR). Toxic Substances Portal.

Baez, A., Padilla, H., Garcia, R., Torres Mdel, C., Rosas, I. and Belmont, R. (2003). Carbonyl levels in indoor and outdoor air in Mexico City and Xalapa, Mexico. Sci. Total Environ. 302: 211-226.

CARB/OEHHA (2017). California environmental protection agency, air resources board and office of environmental health hazard assessment (CARB/OEHHA), consolidated table of OEHHA/ARB approved risk assessment health values.

Chang, T., Wang, J., Lu, J., Shen, Z., Huang, Y., Sun, J., $\mathrm{Xu}, \mathrm{H}$. , Wang, X., Ren, D. and Cao, J. (2019). Evaluation of indoor air pollution during decorating process and inhalation health risks in Xi'an, China: A case study. Aerosol Air Qual. Res. 19: 854-864.

Chen, C.Y., Kuo, Y.C., Wang, S.M., Wu, K.R., Chen, Y.C. and Tsai, P.J. (2019). Techniques for predicting exposures to polycyclic aromatic hydrocarbons (PAHs) emitted from cooking processes for cooking workers. Aerosol Air Qual. Res. 19: 307-317.

Chen, Y.C., Ramachandran, G., Alexander, B.H. and Mandel, J.H. (2012). Retrospective exposure assessment in a chemical research and development facility. Environ. Int. 39: 111-121.

Cheng, J.C., Cui, T., He, W.Q., Nie, L., Wang, J.L. and Pan, T. (2015). Pollution characteristics of aldehydes and ketones compounds in the exhaust of Beijing typical restaurants. J. Environ. Sci - China 36: 2743-2749.

Cheng, J.H., Lee, Y.S. and Chen, K.S. (2016). Carbonyl compounds in dining areas, kitchens and exhaust streams in restaurants with varying cooking methods in Kaohsiung, Taiwan. J. Environ. Sci. 41: 218-226.

Chiu, Y.L., Yu, I.T. and Wong, T.W. (2004). Time trends of female lung cancer in Hong Kong: Age, period and birth cohort analysis. Int J. Cancer 111: 424-430.

Dai, W., Zhong, H., Li, L., Cao, J., Huang, Y., Shen, M., Wang, L., Dong, J., Tie, X., Ho, S.S.H. and Ho, K.F. (2018). Characterization and health risk assessment of airborne pollutants in commercial restaurants in Northwestern China: Under a low ventilation condition in wintertime. Sci. Total Environ. 633: 308-316.

Du, Z., Mo, J. and Zhang, Y. (2014). Risk assessment of population inhalation exposure to volatile organic compounds and carbonyls in urban China. Environ. Int. 73: 33-45.

Dutta, A., Bhattacharya, P., Lahiri, T. and Ray, M.R. (2012). Immune cells and cardiovascular health in premenopausal women of rural india chronically exposed to biomass smoke during daily household cooking. Sci. Total Environ. 438: 293-298.

Fullana, A., Carbonell-Barrachina, A.A. and Sidhu, S. (2004a). Comparison of volatile aldehydes present in the cooking fumes of extra virgin olive, olive, and canola oils. J. Agric. Food Chem. 52: 5207-5214.

Fullana, A., Carbonell-Barrachina, Á.A. and Sidhu, S. (2004b). Volatile aldehyde emissions from heated cooking oils. J. Sci. Food Agric. 84: 2015-2021.

Gao, J., Cao, C., Zhang, X. and Luo, Z. (2013). Volumebased size distribution of accumulation and coarse particles $\left(\mathrm{PM}_{0.1-10}\right)$ from cooking fume during oil heating. Build. Environ. 59: 575-580.

Guerra, F.D., Smith, J.G.D., Alexis, F. and Whitehead, D.C. (2017). A survey of VOC emissions from rendering plants. Aerosol Air Qual. Res. 17: 209-217.

Ho, S.S.H., Yu, J.Z., Chu, K.W. and Yeung, L.L. (2006). Carbonyl emissions from commercial cooking sources in Hong Kong. J. Air Waste Manage. Assoc. 56: 10911098.

Huang, Y., Ho, S.S.H., Ho, K.F., Lee, S.C., Yu, J.Z. and Louie, P.K.K. (2011). Characteristics and health impacts of VOCs and carbonyls associated with residential cooking activities in Hong Kong. J. Hazard. Mater. 186: 344-351.

IARC (2006). Overall evaluation of carcinogenicity to humans, formaldehyde. Monographs Series, International Agency for Research on Cancer, Lyon, France. 88.

Klein, F., Pieber, S.M., Ni, H., Stefenelli, G., Bertrand, A., Kilic, D., Pospisilova, V., Temime-Roussel, B., Marchand, N., El Haddad, I., Slowik, J.G., Baltensperger, U., Cao, J., Huang, R.J. and Prévôt, A.S.H. (2018). Characterization of gas-phase organics using proton transfer reaction timeof-flight mass spectrometry: Residential coal combustion. Environ. Sci. Technol. 52: 2612-2617.

Ko, Y.C., Lee, C.H., Chen, M.J., Huang, C.C., Chang, W.Y., Lin, H.J., Wang, H.Z. and Chang, P.Y. (1997). Risk factors for primary lung cancer among nonsmoking women in Taiwan. Int. J. Epidemiol. 26: 24-31.

Kumar, R., Nagar, J.K., Raj, N., Kumar, P., Kushwah, A.S., Meena, M. and Gaur, S.N. (2008). Impact of domestic air pollution from cooking fuel on respiratory allergies in children in India. Asian Pac. J. Allergy 26: 213-222.

Lin, J.M. and Liou, S.J. (2000). Aliphatic aldehydes produced by heating chinese cooking oils. Bull. Environ. Contam. Toxicol. 64: 817-824.

Liu, Y.Y., Lin, T.C., Wang, Y.J. and Ho, W.L. (2009). Carbonyl compounds and toxicity assessments of emissions from a diesel engine running on biodiesels. $J$. Air Waste Manage. Assoc. 59: 163-171.

Lü, H. and Liu, Y. (2016). Levels and health risk of carbonyl compounds in air of the library in Guangzhou, South China. Aerosol Air Qual. Res. 16: 1234-1243.

MOHW (2015). National insurance administration, statistics of national insurance data in 2015.

Muller, K., Pelzing, M., Gnauk, T., Kappe, A., Teichmann, U., Spindler, G., Haferkorn, S., Jahn, Y. and Herrmann, H. (2002). Monoterpene emissions and carbonyl compound air concentrations during the blooming period of rape (Brassica napus). Chemosphere 49: 1247-1256.

Murillo, J.H., Marín, J.F.R. and Román, S.R. (2012). Determination of carbonyls and their sources in three sites of the metropolitan area of Costa Rica, Central 
America. Environ. Monit. Assess. 184: 53-61.

Nayek, S. and Padhy, P.K. (2017). Daily personal exposure of women cooks to respirable particulate matters during cooking with solid bio-fuels in a rural community of West Bengal, India. Aerosol Air Qual. Res. 17: 245-252.

Peng, C.Y., Lan, C.H., Lin, P.C. and Kuo, Y.C. (2017). Effects of cooking method, cooking oil, and food type on aldehyde emissions in cooking oil fumes. J. Hazard. Mater. 324: 160-167.

Perez-Padilla, R., Perez-Guzman, C., Baez-Saldana, R. and Torres-Cruz, A. (2001). Cooking with biomass stoves and tuberculosis: A case control study. Int. J. Tuberc. Lung Dis. 5: 441-447.

Popovicheva, O.B., Shonija, N.K., Persiantseva, N., Timofeev, M., Diapouli, E., Eleftheriadis, K., Borgese, L., Nguyen, X.A. (2017) Aerosol pollutants during agricultural biomass burning: a case study in $\mathrm{Ba} \mathrm{Vi}$ Region in Hanoi, Vietnam. Aerosol Air Qual. Res. 17: 2762-2779.

Ramírez, N., Cuadras, A., Rovira, E., Borrull, F. and Marcé, R.M. (2012). Chronic risk assessment of exposure to volatile organic compounds in the atmosphere near the largest mediterranean industrial site. Environ. Int. 39: 200-209.

Sarigiannis, D.A., Karakitsios, S.P., Gotti, A., Liakos, I.L. and Katsoyiannis, A. (2011). Exposure to major volatile organic compounds and carbonyls in european indoor environments and associated health risk. Environ. Int. 37: 743-765.

Sarkar, C., Chatterjee, A., Majumdar, D., Roy, A., Srivastava, A., Ghosh, S.K. and Raha, S. (2017). How the atmosphere over eastern Himalaya, India is polluted with carbonyl compounds? temporal variability and identification of sources. Aerosol Air Qual. Res. 17: 2206-2223.

Schauer, J.J., Kleeman, M.J., Cass, G.R. and Simoneit, B.R.T. (2001). Measurement of emissions from air pollution sources. 3. $\mathrm{C}_{1}-\mathrm{C}_{29}$ organic compounds from fireplace combustion of wood. Environ. Sci. Technol. 35: $1716-1728$.

Schauer, J.J., Kleeman, M.J., Cass, G.R. and Simoneit, B.R.T. (2002). Measurement of emissions from air pollution sources. 4. $\mathrm{C}_{1}-\mathrm{C}_{27}$ organic compounds from cooking with seed oils. Environ. Sci. Technol. 36: 567-575.

Shields, P.G., Xu, G.X., Blot, W.J., Fraumeni, J.F., Jr., Trivers, G.E., Pellizzari, E.D., Qu, Y.H., Gao, Y.T. and Harris, C.C. (1995). Mutagens from heated Chinese and U.S. cooking oils. J. Natl. Cancer Inst. Monogr.87: 836-841.

Smith, K.R., Samet, J.M., Romieu, I. and Bruce, N. (2000). Indoor air pollution in developing countries and acute lower respiratory infections in children. Thorax 55: 518-532.

Sun, S.Y., Guang Jiang, W. and Ping Zhao, Y. (2010). Profile of volatile compounds in 12 Chinese soy sauces produced by a high-salt-diluted state fermentation. $J$. Inst. Brew. 116: 316-328.

Svendsen, K., Jensen, H.N., Sivertsen, I. and Sjaastad, A.K. (2002). Exposure to cooking fumes in restaurant kitchens in Norway. Ann. Occup. Hyg. 46: 395-400.

Tsai, J.H., Yao, Y.C., Huang, P.H. and Chiang, H.L. (2018). Fuel economy and volatile organic compound exhaust emission for motorcycles with various running mileages. Aerosol Air Qual. Res. 18: 3056-3067.

U.S. EPA (1991). The clean air act. Office of research and development, Washington, DC.

U.S. EPA (2011). Exposure factors handbook. National Center For Environmental Assessment, Washington, DC, http:/www.epa.gov/ncea/efh, Last Access: 07 June 2019.

U.S. EPA-IRIS (2017). Integrated risk information system (IRIS). United States Environmental Protection Agency.

Villanueva, F., Tapia, A., Amo-Salas, M., Notario, A., Cabanas, B. and Martinez, E. (2015). Levels and sources of volatile organic compounds including carbonyls in indoor air of homes of Puertollano, the most industrialized city in Central Iberian Peninsula. estimation of health risk. Int. J. Hyg. Environ. Health 218: 522-534.

Villanueva-Fierro, I., Popp, C.J. and Martin, R.S. (2004). Biogenic emissions and ambient concentrations of hydrocarbons, carbonyl compounds and organic acids from ponderosa pine and cottonwood trees at rural and forested sites in Central New Mexico. Atmos. Environ. 38: 249-260.

Wang, H.K., Huang, C.H., Chen, K.S. and Peng, Y.P. (2010). Seasonal variation and source apportionment of atmospheric carbonyl compounds in urban Kaohsiung, Taiwan. Aerosol Air Qual. Res. 10: 559-570.

Wildt, J., Kobel, K., Schuh-Thomas, G. and Heiden, A.C. (2003). Emissions of oxygenated volatile organic compounds from plants part II: Emissions of saturated aldehydes. J. Atmos. Chem. 45: 173-196.

Winberry, W.T., Jr. (1990). Methods for determination of toxic organic compounds in air. Park Ridge, NJ (United States); Noyes Publications, United States.

Xiang, Z., Wang, H., Stevanovic, S., Jing, S., Lou, S., Tao, S., Li, L., Liu, J., Yu, M. and Wang, L. (2017). Assessing impacts of factors on carbonyl compounds emissions produced from several typical Chinese cooking. Build. Environ. 125: 348-355.

Xue, Y., Jiang, Y., Jin, S. and Li, Y. (2016). Association between cooking oil fume exposure and lung cancer among Chinese nonsmoking women: A meta-analysis. Onco Targets Ther. 9: 2987-2992.

Yao, Z., Li, J., Wu, B., Hao, X., Yin, Y. and Jiang, X. (2015). Characteristics of PAHs from deep-frying and frying cooking fumes. Environ. Sci. Pollut. Res. 22: 16110-16120.

Yu, I.T., Chiu, Y.L., Au, J.S., Wong, T.W. and Tang, J.L. (2006). Dose-response relationship between cooking fumes exposures and lung cancer among Chinese nonsmoking women. Cancer Res. 66: 4961-4967.

Zhang, J. and Smith, K.R. (1999). Emissions of carbonyl compounds from various cookstoves in China. Environ. Sci. Technol. 33: 2311-2320.

Zhang, J., Wu, L., Fang, X., Li, F., Yang, Z., Wang, T., Mao, H. and Wei, E. (2018). Elemental composition and health risk assessment of $\mathrm{PM}_{10}$ and $\mathrm{PM}_{2.5}$ in the roadside 
microenvironment in Tianjin, China. Aerosol Air Qual. Res. 18: 1817-1827

Zhang, Y. and Tao, W. (2009). Flavor and taste compounds analysis in Chinese solid fermented soy sauce. Afr. J. Biotechnol. 8: 673-681.
Received for review, June 5, 2019

Revised, June 20, 2019

Accepted, June 20, 2019 